Pacific Journal of Mathematics

DUGUNDJI EXTENSION THEOREMS FOR LINEARLY 


\title{
DUGUNDJI EXTENSION THEOREMS FOR LINEARLY ORDERED SPACES
}

\author{
R. W. Heath and D. J. Lutzer
}

In this paper we prove a Dugundji Extension Theorem for a large class of monotonically normal spaces, the generalized ordered spaces. We show that if $A$ is a closed subset of a generalized ordered space $X$ and if $C^{*}(A)$ and $C^{*}(X)$ denote the vector spaces of continuous, bounded real-valued functions on $A$ and $X$ respectively, then there is a linear transformation $u: C^{*}(A) \rightarrow C^{*}(X)$ such that for each $g \in C^{*}(A), u(g)$ extends $g$ and the range of $u(g)$ is contained in the closed convex hull of the range of $g$. Furthermore, we give an example which shows that such linear transformations from $C(A)$, the vector space of all continuous, real-valued functions on $A$, to $C(X)$ cannot always be found, even when $A$ is a closed, separable metrizable subspace of a hereditarily paracompact linearly ordered space.

1. Introduction. For any space $S$, let $C(S)$ be the vector space of all continuous, real-valued functions on $S$ and let $C^{*}(S)$ be the space of all bounded members of $C(S)$. In [4], Dugundji proved that if $A$ is a closed subset of a metrizable space $X$, then there is a linear transformation $u: C(A) \rightarrow C(X)$ such that for each $g \in C(A)$ :

(a) $u(g)$ is an extension of the function $g$; and

(b) the range of $u(g)$ is a subset of the closed convex hull of the range of $g$.

We shall call $u$ a simultaneous extender from $C(A)$ to $C(X)$; the notion of a simultaneous extender from $C^{*}(A)$ to $C^{*}(X)$ is analogously defined ${ }^{1}$.

Subsequent generalizations of Dugundji's theorem have relaxed the requirement that $X$ be metrizable and have considered functions having values in a locally convex topological vector space $[1,2,3,10,12,13]$. The largest class of spaces for which a Dugundji Extension Theorem has been proved is the class of stratifiable spaces [3] (which includes all metric spaces). Recently, a theorem reminiscent of Dugundji's result has been obtained for the still larger class of monotonically normal spaces [6]. In this paper we present a Dugundji Extension Theorem for a large and important subclass of the monotonically normal spaces, vis., the generalized ordered spaces. Our theorem,

1 It is interesting to note that if $A$ is a closed subset of a normal space $X$, then there will always exist linear transformations $u: C(A) \rightarrow C(X)$ such that $u(g)$ extends $g$ for each $g \in C(A)$ : this may be deduced from the Tietze extension theorem by considering a Hamel base for the real vector space $C(A)$. 
unlike some of the ones mentioned above $[1,2,3,10,12]$, deals with simultaneous extenders from $C^{*}(A)$ to $C^{*}(X)$ and an example in $\S 3$ shows that it is not always possible to obtain simultaneous extenders from $C(A)$ to $C(X)$, even when $X$ is hereditarily paracompact and such extenders from $C^{*}(A)$ to $C^{*}(X)$ are known to exist.

A linearly ordered topological space is a linearly ordered set endowed with the usual open-interval topology of the linear order. A generalized ordered space is a linearly ordered set $X$ endowed with a topology having a base $\mathscr{B}$ every member of which is an interval (open, closed, half-open and degenerate intervals are allowed) and which contains all open intervals of $X$. The generalized ordered spaces may also be characterized as those spaces which can be embedded in linearly ordered spaces; spaces of this type were studied in [8] and it is known that any generalized ordered space is monotonically normal [6]. Perhaps the most familiar pathological generalized ordered spaces are the Sorgenfrey line (3.1) and the Michael line (3.3).

2. The extension theorem for bounded functions. The key to our extension theorem is the notion of a Banach limit. Let us begin by recalling some definitions.

Definition 2.1. Let $(D, \leqq)$ be a directed set [7] and let $f$ be a bounded, real-valued function on $D$. Then

$$
\begin{aligned}
\limsup _{D}(f) & =\inf \{\sup \{f(x): x \geqq y\}: y \in D\} \quad \text { and } \\
\liminf _{D}(f) & =\sup \{\inf \{f(x): x \geqq y\}: y \in D\} .
\end{aligned}
$$

If $\limsup _{D}(f)=\liminf _{D}(f)$, then we define $\lim _{D}(f)=\limsup _{D}(f)$.

Lemma 2.2. Let $(D, \leqq)$ be a directed set and let $V$ be the vector space of all bounded, real-valued functions on the set $D$. Then there is a linear transformation $L: V \rightarrow R$, the space of real numbers, such that

(a) for any $f \in V$, $\liminf _{D}(f) \leqq L(f) \leqq \limsup _{D}(f)$;

(b) if $\lim _{D}(f)$ exists, then $L(f)=\lim _{D}(f)$.

Proof. See [15; p. 104].

REMARK 2.3. In the classical case of this result, $D$ is the set of positive integers and the functional $L$ is called a Banach limit. We shall call the functional $L$ in 2.2 a Banach limit over $D$. Observe that if the directed set $(D, \leqq)$ has a last element $d^{\prime}$, then $L(f)=$ $f\left(d^{\prime}\right)$ for each $f$ in $V$. In our applications, the set $D$ will carry a linear ordering. 
THeOREM 2.4. Let $A$ be a closed subset of a generalized ordered space $X$. Then there is a simultaneous extender $u: C^{*}(A) \rightarrow C^{*}(X)$.

Proof. Let $\mathscr{J}=\left\{I_{\gamma}: \gamma \in \Gamma\right\}$ be the collection of all convex components of set $X \backslash A .^{2}$ For each $\gamma \in \Gamma$ let $A_{\gamma}^{+}=\{a \in A: a \geqq x$ for each $\left.x \in I_{\gamma}\right\}$ and let $A_{\gamma}^{-}=\left\{\alpha \in A: \alpha \leqq x\right.$ for each $\left.x \in I_{\gamma}\right\}$. Using the ordering inherited from $X, A_{\bar{\gamma}}^{-}$is a directed set; using the reverse of the ordering inherited from $X, A_{r}^{+}$is also a directed set. Provided $A_{r}^{+} \neq \varnothing$, let $L_{\gamma}^{+}$be a Banach limit over $A_{r}^{+}$; provided $A_{r}^{-} \neq \varnothing$, let $L_{\gamma}^{-}$be a Banach limit over $A_{r}^{-}$. For each $\gamma \in \Gamma$, let $\psi_{\gamma}: X \rightarrow[0,1]$ be a continuous function such that

(i) $\left\{x \in X: x<y\right.$ for each $\left.y \in I_{r}\right\} \subset \psi_{r}^{-1}(1)$

(ii) $\left\{x \in X: x>y\right.$ for each $\left.y \in I_{\gamma}\right\} \subset \psi_{\gamma}^{-1}(0)$

(iii) if $I_{\gamma}$ has at least two points, then there are points $r_{\gamma}$ and $s_{\gamma}$ of $I_{\gamma}$ having $r_{\gamma}<s_{\gamma}$ and

$$
\left(\longleftarrow, r_{\gamma}\right] \subset \psi_{\gamma}^{-1}(1) \text { and }\left[s_{\gamma}, \longrightarrow\right) \subset \psi_{\gamma}^{-1}(0) \text {. }
$$

For each $f \in C^{*}(A)$, define $\hat{f}$ on $X$ by

$$
\hat{f}(x)=\left\{\begin{array}{l}
f(x) \text { if } x \in A ; \\
\psi_{\gamma}(x) L_{\gamma}^{-}(f)+\left(1-\psi_{\gamma}(x)\right) L_{r}^{+}(f) \text { if } x \in I_{\gamma} \text { and } A_{r}^{+} \neq \varnothing \neq A_{\gamma}^{-} ; \\
L_{\gamma}^{+}(f) \text { if } x \in I_{\gamma} \text { and } A_{\gamma}^{-}=\varnothing ; \\
L_{\gamma}^{-}(f) \text { if } x \in I_{\gamma} \text { and } A_{\gamma}^{+}=\varnothing .
\end{array}\right.
$$

Then $\hat{f}: X \rightarrow R$ is continuous and $\hat{f}(X) \subset \operatorname{cl}_{R}\{r \in R$ : for some $a, b \in A$, $f(a) \leqq r \leqq f(b)\}$, the closed convex hull of the set $f(A)$. Hence $\hat{f} \in$ $C^{*}(X)$. Therefore, if we define $u(f)=\hat{f}$, we obtain the required simultaneous extender.

REMARKS 2.5. It is clear that the simultaneous extender found in 2.4 preserves constant functions and that if $C^{*}(A)$ and $C^{*}(X)$ are each equipped with the sup-norm, then the simultaneous extender is a linear operator of norm 1.

3. Extending unbounded functions. We begin this section with examples showing that simultaneous extension of all continuous real-valued functions is sometimes possible in spaces which are not stratifiable.

ExAmple 3.1. Let $A$ be any closed subset of the Sorgenfrey line

${ }^{2}$ A subset $S$ of a linearly ordered set $X$ is convex provided $[a, b] \subset S$ whenever $a$ and $b$ are points of $S$ having $a \leqq b$. A subset $S$ of a set $T$ in $X$ is called a convex component of $T$ provided $S$ is a convex subset of $X, S \subset T$ and no strictly larger convex subset of $X$ is a subset of $T$. Clearly any subset of $X \mathrm{c}$ an be uniquely expressed as a union of its convex components. 
$X$ [14], i.e., the set of real numbers topologized in such a way that for each real number $x$, the collection $\{[x, x+t): t>0\}$ is an open neighborhood base at $x$. Then there is a simultaneous extender $u: C(A) \rightarrow C(X)$. For consider $\mathscr{J}=\left\{I_{r}: \gamma \in \Gamma\right\}$, the family of all convex components of $X \backslash A,{ }^{2}$ and choose $a_{0} \in A$. Each $I_{r}$ will have one of the five forms described in the following definition: for any $g \in C(A)$, define $\hat{g}: X \rightarrow R$ by

$$
\hat{g}(x)=\left\{\begin{array}{l}
g(x) \text { if } x \in A ; \\
g\left(a_{\gamma}\right) \text { if } x \in I_{\gamma}=\left(a_{\gamma}, b_{\gamma}\right) \text { or if } x \in I_{\gamma}=\left(a_{\gamma},+\infty\right) ; \\
g\left(b_{\gamma}\right) \text { if } x \in I_{\gamma}=\left[a_{\gamma}, b_{\gamma}\right) \text { or if } x \in I_{r}=\left(-\infty, b_{\gamma}\right) ; \\
g\left(a_{0}\right) \text { if } x \in I_{\gamma}=\left[a_{\gamma},+\infty\right) .
\end{array}\right.
$$

Defining $u(g)=\hat{g}$, we obtain the required simultaneous extender from $C(A)$ to $C(X)$.

Because the Sorgenfrey line is not metrizable, it is not stratifiable [8; Theorem 5.3].

Our second example shows that a space may satisfy a Dugundji Extension Theorem without being paracompact or perfectly normal.

EXAMPLE 3.2. Let $X$ be the usual space of countable ordinals [7]. For any closed subset $A \subset X$ there exist simultaneous extenders from $C(A)$ to $C(X)$. Theorem 2.4 provides a proof of this fact since $C^{*}(A)=$ $C(A)$ and $C^{*}(X)=C(X)$.

Our final example shows that simultaneous extenders from $C(A)$ to $C(Y)$ may fail to exist even when $A$ is a closed, separable metrizable subspace of a hereditarily paracompact linearly ordered space $Y$ (whence simultaneous extenders from $C^{*}(A)$ to $C^{*}(X)$ do exist). In our example, $P, Q$, and $R$ will denote the sets of irrational, rational and real numbers, respectively.

ExAmple 3.3. Let $X$ be the Michael line [11], i.e., the set of real numbers endowed with the topology $\mathscr{C}=\{U \cup V: U$ is open in the usual topology of $R$ and $V \subset P\}$. Let $A=Q$. Then there is no simultaneous extender $u: C(A) \rightarrow C(X)$.

We argue indirectly. Enumerate $A$ as $A=\left\{r_{n}: n \geqq 1\right\}$ and suppose there were a simultaneous extender $u: C(A) \rightarrow C(X)$. For any $g \in C(A)$, denote $u(g)$ by $\hat{g}$.

Let $a_{0}=-\pi$ and $b_{0}=\pi$. Define $f_{1} \in C(A)$ by

$$
f_{1}(x)=\left\{\begin{array}{l}
1 \text { if } x A \backslash\left[a_{0}, b_{0}\right] \\
0 \text { if } x \in A \cap\left[a_{0}, b_{0}\right] .
\end{array}\right.
$$


Then there are irrational numbers $a_{1}<b_{1}$ such that $\left[a_{1}, b_{1}\right] \subset\left(a_{0}, b_{0}\right) \backslash\left\{r_{1}\right\}$ and such that $\hat{f}_{1}\left(\left[a_{1}, b_{1}\right]\right) \subset[0,1 / 4]$ because the set $\left\{x \in\left[a_{0}, b_{0}\right]: \hat{f}_{1}(x) \geqq 1 / 4\right\}$ is nowhere dense in $\left[a_{0}, b_{0}\right]$ with its usual topology. Inductively construct irrational numbers $a_{n}<b_{n}$ and functions $f_{n} \in C(A)$ satisfying:

(1) $\left[a_{n}, b_{n}\right] \subset\left(a_{n-1}, b_{n-1}\right) \backslash\left\{r_{n}\right\}$;

(2) for $n \geqq 2$,

$$
f_{n}(x)=\left\{\begin{array}{lll}
1 / 2^{n-1} & \text { if } & x \in A \cap\left(\left[a_{n-2}, b_{n-2}\right] \backslash\left[a_{n-1}, b_{n-1}\right]\right) \\
0 & \text { if } & x \in A \backslash\left(\left[a_{n-2}, b_{n-2}\right] \backslash\left[a_{n-1}, b_{n-1}\right]\right)
\end{array}\right.
$$

(3) $\left(\sum_{i=1}^{n} \hat{f}_{i}\right)\left(\left[a_{n}, b_{n}\right]\right) \subset\left[0,1 / 2^{n+1}\right]$.

It follows from (1) that $\bigcap\left\{\left[a_{n}, b_{n}\right]: n \geqq 1\right\}$ consists of a single irrational number $c$. Let $g=\sum\left\{f_{n}: n \geqq 1\right\}$. Then $g \in C^{*}(A)$ because the series $\sum\left\{f_{n}: n \geqq 1\right\}$ converges uniformly. Furthermore, because the range of $g-\sum\left\{f_{i}: 1 \leqq i \leqq n\right\}$ is a subset of $\left[0,1 / 2^{n}\right]$, so is the range of $u\left(g-\sum\left\{f_{i}: 1 \leqq i \leqq n\right\}\right)=\widehat{g}-\sum\left\{\hat{f}_{i}: 1 \leqq i \leqq n\right\}$; hence $\hat{g}=$ $\sum\left\{\hat{f}_{n}: n \geqq 1\right\}$ so that $\hat{g}(c)=0$.

Define $h \in C(A)$ by $h(x)=1+1 /(|x-c|)$ and let $k$ be the number $\hat{h}(c)$. There is an $\varepsilon>0$ such that $h(x)>k+1$ whenever $x \in A \cap[c-\varepsilon$, $c+\varepsilon]$. Let $m$ be the minimum value of $g(x)$ on the set $A \backslash[c-\varepsilon, c+\varepsilon]$. Then $m>0$ so that, for some positive integer $N, N m>k+1$. Therefore, the range of the function $h+N g$ is a subset of $[k+1,+\infty)$; hence the same is true of the function $\hat{h}+N \hat{g}$. But that is impossible since $(\hat{h}+N \hat{g})(c)=k$.

To obtain the hereditarily paracompact linearly ordered space in which simultaneous extenders for unbounded functions cannot be found, observe that there is a linearly ordered space $Y$ which contains the Michael line $X$ as a closed subspace and which is also hereditarily paracompact (in the notation of [8], $Y=X^{*}$ ).

REMARK 3.4. Example 3.3 shows that the assertion on page 806 of [10] that simultaneous extenders from $C(A)$ to $C(X)$ can be found provided $A$ is a closed metrizable subspace of a paracompact space $X$ is erroneous. The correct statement is that if $A$ is a closed, metrizable, $G_{\tilde{\delta}}$-subspace of the paracompact space $X$ then simultaneous extenders from $C(A)$ to $C(X)$ exist [9].

Our final theorem contrasts with the situation in 3.3 and illustrates the special role of perfect normality in generalized ordered spaces; see also [8; Theorem 4.8].

TheOREM 3.5. Suppose that $A$ is a closed subset of a perfectly normal generalized ordered space $X$. If $A$ is $\sigma$-compact, then there is a simultaneous extender from $C(A)$ to $C(X)$.

Our proof requires two lemmas. 
LEMMA 3.6. Let $A$ be a closed, $\sigma$-compact subset of a generalized ordered space $X$. Suppose that $X \backslash A$ is an $F_{\sigma}$-subset of $X$ and that each convex component of $X \backslash A$ is closed in $X$. Then there is a simultaneous extender from $C(A)$ to $C(X)$.

Proof. Let $\left\{I_{\gamma}: \gamma \in \Gamma\right\}$ be the family of all convex components of $X \backslash A$. Write $X \backslash A=\bigcup\left\{F_{n}: n \geqq 1\right\}$ where each $F_{n}$ is closed in $X$ and let $\Gamma_{n}^{\prime}=\left\{\gamma \in \Gamma: I_{r} \cap F_{n} \neq \varnothing\right\}$. Let $\Gamma_{1}=\Gamma_{1}^{\prime}$ and for $n \geqq 1$ let $\Gamma_{n+1}=\Gamma_{n+1}^{\prime} \backslash \bigcup\left\{\Gamma_{i}: 1 \leqq i \leqq n\right\}$. Then each collection $\left\{I_{\gamma}: \gamma \in \Gamma_{n}\right\}$ is a discrete collection of closed and open subsets of $X$.

Write $A=\bigcup\left\{A_{n}: n \geqq 1\right\}$ where $A_{1} \subset A_{2} \subset \cdots$ are compact sets. For each $n \geqq 1$ let $u_{n}: C\left(A_{n}\right) \rightarrow C(X)$ be the simultaneous extender constructed in 2.4. For each $g \in C(A)$ define $\hat{g}$ on $X$ by

$$
\widehat{g}(x)=\left\{\begin{array}{l}
g(x) \text { if } \quad x \in A ; \\
u_{n}\left(g / A_{n}\right)(x) \text { if } \quad x \in \bigcup\left\{I_{\gamma}: \gamma \in \Gamma_{n}\right\} .
\end{array}\right.
$$

Because the collections $\Gamma_{n}$ are pairwise disjoint, $\hat{g}(x)$ is well-defined. Furthermore, $\hat{g}$ is continuous because each $u_{n}$ has the following property, as may be seen from the proof of 2.4: if $a<b$ are points of $A_{n}$ and if $f \in C\left(A_{n}\right)$, then $\left(u_{n}(f)\right)([a, b])$ is contained in the closed convex hull of the set $f\left(A_{n} \cap[a, b]\right)$. Then, defining $u(g)=\hat{g}$, we obtain the required simultaneous extender.

Lemma 3.7. Suppose that $B$ is a closed subset of the generalized ordered space $X$ and that no convex component of $X \backslash B$ is closed in $X$. Then there is a simultaneous extender from $C(B)$ to $C(X)$.

Proof. Let $\left\{I_{\gamma}: \gamma \in \Gamma\right\}$ be the family of convex components of $X \backslash B$. Each set $I_{\gamma}$ must have either one or two limit points in $B$ and these limit points must be end-points of $I_{r}$. If $I_{\gamma}$ has a right endpoint which belongs to $B$, denote it by $b_{r}^{+}$; if $I_{\gamma}$ has a left end-point which belongs to $B$, denote it by $b_{\gamma}^{-}$. If both $b_{r}^{+}$and $b_{\gamma}^{-}$exist, choose a continuous function $\psi_{\gamma}: X \rightarrow[0,1]$ having $\psi_{\gamma}\left(\left\{x \in X: x \leqq b_{\gamma}^{-}\right\}\right)=0$ and $\psi_{\gamma}\left(\left\{x \in X: x \geqq b_{\gamma}^{+}\right\}\right)=1$. For each $g \in C(B)$ define $\hat{g}$ on $X$ by

$$
\hat{g}(x)=\left\{\begin{array}{l}
g(x) \text { if } x \in B ; \\
g\left(b_{\gamma}^{-}\right) \text {if } x \in I_{\gamma} \text { and } b_{\gamma}^{-}, \text {but not } b_{\gamma}^{+}, \text {exists; } \\
g\left(b_{\gamma}^{+}\right) \text {if } x \in I_{\gamma} \text { and } b_{\gamma}^{+}, \text {but not } b_{\gamma}^{-}, \text {exists; } \\
\psi_{\gamma}(x) g\left(b_{\gamma}^{+}\right)+\left(1-\psi_{\gamma}(x)\right) g\left(b_{\gamma^{-}}\right) \text {if } x \in I_{\gamma} \\
\text { and both } b_{\gamma}^{+} \text {and } b_{\gamma}^{-} \text {exist } .
\end{array}\right.
$$

Then $\hat{g}(x)$ is well-defined and continuous, and the required simultaneous extender is obtained by defining $u(g)=\hat{g}$. 
Proof of Theorem 3.5. Let $\left\{I_{\gamma}: \gamma \in \Gamma\right\}$ be the family of all convex components of $X \backslash A$ and let $\Gamma_{1}=\left\{\gamma \in \Gamma: I_{\gamma}\right.$ is closed in $\left.X\right\}$. Let $X_{1}=$ $A \cup\left(\cup\left\{I_{\gamma}: \gamma \in \Gamma_{1}\right\}\right)$ and apply 3.6 to the closed subset $A$ of the generalized ordered space $X_{1}$ to obtain a simultaneous extender $u_{1}: C(A) \rightarrow$ $C\left(X_{1}\right)$. Observe that $X_{1}$ is a closed subset of $X$ and that no convex component of $X \backslash X_{1}$ is closed in $X$. Apply 3.7 to find a simultaneous extender $u_{2}: C\left(X_{1}\right) \rightarrow C(X)$. Then the composite function $u=u_{2} \circ u_{1}$ is the required simultaneous extender from $C(A)$ to $C(X)$.

Let us conclude with some questions suggested by the results above; further questions related to the Dugundji Extension Theorem may be found in [5].

(1) If $A$ is a closed subspace of a perfectly normal generalized ordered space $X$, must there be a simultaneous extender from $C(A)$ to $C(X)$ ? What if $X$ is assumed to be linearly ordered?

(2) Is there an analogue of Theorem 2.4 for functions with values in a locally convex topological vector space?

\section{REFERENCES}

1. R. Arens, Extension of functions on fully normal spaces, Pacific J. Math., 2 (1952), $11-22$.

2. C. R. Borges, On stratifiable spaces, Pacific J. Math., 17 (1966), 1-16.

3. J. G. Ceder, Some generalizations of metric spaces, Pacific J. Math., 11 (1961), 105-125.

4. J. Dugundji, An extension of Tietze's theorem, Pacific J. Math., 1 (1951), 353-367.

5. R. W. Heath, Remarks on Dugundji extension theorems, Proceedings of the Second

Pittsburgh Topology Conference. Springer-Verlag Lecture Notes in Mathematics, $\$ 378$, New York, 1975.

6. R. W. Heath, D. Lutzer, and P. Zenor, On monotonically normal spaces, Trans. Amer. Math. Soc., 178 (1973), 481-493.

7. J. L. Kelley, General Topology, Van Nostrand, New York, 1965.

8. D. J. Lutzer, On generalized ordered spaces, Dissertations Mathematicae (Rozprawy Mat.), 89 (1971), 1-36.

9. D. J. Lutzer and H. Martin, A note on the Dugundji extension theorem, Notices Amer. Math. Soc. Proc. Amer. Math. Soc., 45 (1974), 137-139.

10. E. A. Michael, Some extension theorems for continuous functions, Pacific J. Math., 3 (1953), 789-806.

11. - The product of a normal space and a metric space need not be normal, Bull. Amer. Math. Soc., 69 (1963), 375-376.

12. E. A. Michael and A. Pelczynski, A linear extension theorem, Illinois J. Math., 11 (1967), 563-579.

13. A. Pelczynski, On simultaneous extension of continuous functions, Studia Math., 24 (1964), 285-304.

14. R. H. Sorgenfrey, On the topological product of paracompact spaces, Bull. Amer. Math. Soc., 53 (1947), 631-632.

15. K. Yosida, Functional Analysis, Springer-Verlag, Berlin, 1965.

Received March 28, 1973. Partially supported by NSF grant GP 29401. 



\section{PACIFIC JOURNAL OF MATHEMATICS}

\section{EDITORS}

RICHARD ARENS (Managing Editor)

University of California

Los Angeles, California 90024

\section{R. A. Beaumont \\ University of Washington \\ Seattle, Washington 98105}

\section{J. DugundJI}

Department of Mathematics

University of Southern California

Los Angeles, California 90007

D. Gilbarg and J. Milgram

Stanford University

Stanford, California 94305

\section{ASSOCIATE EDITORS}
E. F. BECKENBACH
B. H. NeumanN
F. WOLF
K. YOSHIDA

\section{SUPPORTING INSTITUTIONS}

UNIVERSITY OF BRITISH COLUMBIA
CALIFORNIA INSTITUTE OF TECHNOLOGY
UNIVERSITY OF CALIFORNIA
MONTANA STATE UNIVERSITY
UNIVERSITY OF NEVADA
NEW MEXICO STATE UNIVERSITY
OREGON STATE UNIVERSITY
UNIVERSITY OF OREGON
OSAKA UNIVERSITY

UNIVERSITY OF BRITISH COLUMBIA

UNIVERSITY OF CALIFORNIA

MONTANA STATE UNIVERSITY

NEW MEXICO STATE UNIVERSITY

OREGON STATE UNIVERSITY

OSAKA UNIVERSITY

\author{
UNIVERSITY OF SOUTHERN CALIFORNIA \\ STANFORD UNIVERSITY \\ UNIVERSITY OF TOKYO \\ UNIVERSITY OF UTAH \\ WASHINGTON STATE UNIVERSITY \\ UNIVERSITY OF WASHINGTON \\ AMERICAN MATHEMATICAL SOCIETY \\ NAVAL WEAPONS CENTER
}

The Supporting Institutions listed above contribute to the cost of publication of this Journal, but they are not owners or publishers and have no responsibility for its content or policies.

Mathematical papers intended for publication in the Pacific Journal of Mathematics should be in typed form or offset-reproduced, (not dittoed), double spaced with large margins. Underline Greek letters in red, German in green, and script in blue. The first paragraph or two must be capable of being used separately as a synopsis of the entire paper. Items of the bibliography should not be cited there unless absolutely necessary, in which case they must be identified by author and Journal, rather than by item number. Manuscripts, in triplicate, may be sent to any one of the editors. Please classify according to the scheme of Math. Reviews, Index to Vol. 39. All other communications should be addressed to the managing editor, or Elaine Barth, University of California, Los Angeles, California, 90024.

The Pacific Journal of Mathematics expects the author's institution to pay page charges, and reserves the right to delay publication for nonpayment of charges in case of financial emergency.

100 reprints are provided free for each article, only if page charges have been substantially paid. Additional copies may be obtained at cost in multiples of 50 .

The Pacific Journal of Mathematics is issued monthly as of January 1966. Regular subscription rate: $\$ 72.00$ a year (6 Vols., 12 issues). Special rate: $\$ 36.00$ a year to individual members of supporting institutions.

Subscriptions, orders for back numbers, and changes of address should be sent to Pacific Journal of Mathematics, 103 Highland Boulevard, Berkeley, California, 94708.

PUBLISHED BY PACIFIC JOURNAL OF MATHEMATICS, A NON-PROFIT CORPORATION

Printed at Kokusai Bunken Insatsusha (International Academic Printing Co., Ltd.), 270, 3-chome Totsuka-cho, Shinjuku-ku, Tokyo 160, Japan.

Copyright (C) 1973 by Pacific Journal of Mathematics Manufactured and first issued in Japan 


\section{Pacific Journal of Mathematics \\ Vol. 55, No. $2 \quad$ October, 1974}

Walter Allegretto, On the equivalence of two types of oscillation for elliptic

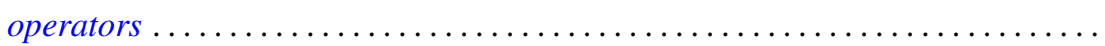

Edward Arthur Bertram, A density theorem on the number of conjugacy classes in

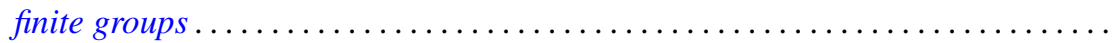

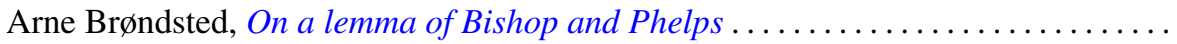

Jacob Burbea, Total positivity and reproducing kernels ..................

Ed Dubinsky, Linear Pincherle sequences . . . . . . . . . . . . . . . . . .

Benny Dan Evans, Cyclic amalgamations of residually finite groups .............

361

Barry J. Gardner and Patrick Noble Stewart, A "going down" theorem for certain

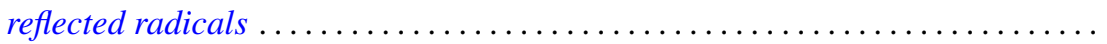

381

Jonathan Light Gross and Thomas William Tucker, Quotients of complete graphs:

revisiting the Heawood map-coloring problem ....................

Sav Roman Harasymiv, Groups of matrices acting on distribution spaces .........

Robert Winship Heath and David John Lutzer, Dugundji extension theorems for

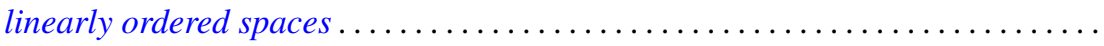

Chung-Wu Ho, Deforming p. l. homeomorphisms on a convex polygonal

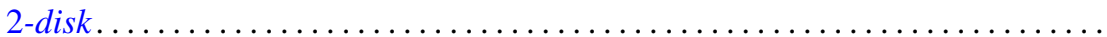

Richard Earl Hodel, Metrizability of topological spaces .................

Wilfried Imrich and Mark E. Watkins, On graphical regular representations of

cyclic extensions of groups .......................... 461

Jozef Krasinkiewicz, Remark on mappings not raising dimension of curves ..... . 479

Melven Robert Krom, Infinite games and special Baire space extensions . . . . . . 483

S. Leela, Stability of measure differential equations . . . . . . . . . . . . . . . . 489

M. H. Lim, Linear transformations on symmetric spaces . . . . . . . . . . . . . . . 499

Teng-Sun Liu, Arnoud C. M. van Rooij and Ju-Kwei Wang, On some group algebra modules related to Wiener's algebra $M_{1} \ldots \ldots \ldots \ldots \ldots \ldots \ldots \ldots \ldots \ldots \ldots$

Dale Wayne Myers, The back-and-forth isomorphism construction ............ 521

Donovan Harold Van Osdol, Extensions of sheaves of commutative algebras by

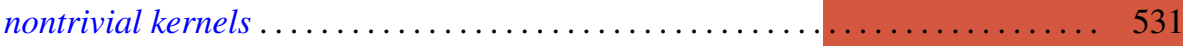

Alan Rahilly, Generalized Hall planes of even order ................... 543

Joylyn Newberry Reed, On completeness and semicompleteness of first countable

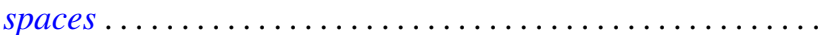

Alan Schwartz, Generalized convolutions and positive definite functions associated

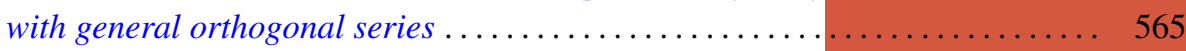

Thomas Jerome Scott, Monotonic permutations of chains . . . . . . . . . . . 583

Eivind Stensholt, An application of Steinberg's construction of twisted groups .... 595

Yasuji Takeuchi, On strongly radicial extensions . . . . ................. 619

William P. Ziemer, Some remarks on harmonic measure in space . . . . . . . . . . 629

John Grant, Corrections to: “Automorphisms definable by formulas” . . . . . . . . 639

Peter Michael Rosenthal, Corrections to: "On an inversion for the general

Mehler-Fock transform pair" ......................... 640

Carl Clifton Faith, Corrections to: "When are proper cyclics injective” . . . . . . 640 